\title{
Surface modification of TC4 Ti alloy by laser cladding with $\mathrm{Ni}$-Ti-Nb powders
}

\author{
Yiming Tian, Chengxin Lin*, Jie Yu, Zhijie Liu, Yu Zhang, and Songjiang Jia \\ School of Naval Architecture and Marine Engineering, Dalian Maritime University, Dalian, Liaoning, \\ 116026, China
}

\begin{abstract}
TC4 Ti alloy with the excellent properties can be applied to many fields, but the surface performance such as wear-resisting, fretting wear, contact corrosion etc.can't be met for many special demands. Laser cladding was applied on a TC4 Ti alloy to improve its properties. Mixed $\mathrm{Ni}, \mathrm{Ti}$ and $\mathrm{Nb}$ powders were put onto the TC4 $\mathrm{Ti}$ alloy and subsequently treated by laser beam. The experimental results show that the surface hardness and wear resistance are significantly improved. The increase in wear resistance is predicted to be related to the "adaptive" wear mechanism of SMA.The microstructure and composition modifications in the surface layer were carefully investigated by using SEM, EDX and metallographic microscope. Experimental analyses show that the compositions of laser cladding coating are close to shape memory alloy of $44 \mathrm{Ni}-47 \mathrm{Ti}-9 \mathrm{Nb}$, and differedt microstructure are rich with different elements. These experimental results are associated with laser processing techniques and alloy composition to some extent.
\end{abstract}

\section{Introduction}

Titanium and titanium alloys are known as "space metal" or "marine metal" due to their excellent properties,such as outstanding corrosion resistance and high specific strength. They are widely used in defense industry and civil industry[1]. However, due to its expensive price,although there has been an increase in the application of new fields such as sports equipment, construction, automobiles, and armor in recent years, no breakthrough has been made. Since TC4 was first developed in 1954 as an equiaxed martensitic two-phase alloy $(\alpha+\beta$ type)[2], it has developed into a universal titanium alloy[3]. Over the years, its fatigue properties has caused more and more attention. With many years of application research at home and abroad, TC4 also shows its some problems and shortcoming such as wear-resisting, fretting wear, contact corrosion etc[4].These performance defects greatly limit the further development of TC4 titanium alloys in many fields[5]. Laser cladding of $\mathrm{Ni}-\mathrm{Ti}-\mathrm{Nb}$ alloy coating technology can improve the performance of TC4 titanium alloy[6][7], and the application of TC4 alloy will be further developed[8].

As an emerging material surface modification and part processing and repair technology, laser cladding technology is an important application aspect of laser processing technology.

* Corresponding author: 1chxin@dlmu.edu.cn 
Using a high-energy laser beam, the coating material that has been previously coated on or transported to the surface is melted together with the surface of the substrate,then rapidly solidified to form a surface coating with a very low dilution ratio and good metallurgical bonding. In this way, the wear resistance, corrosion resistance, heat resistance, and oxidation resistance of the substrate surface are significantly improved[9].

\section{Experimental}

According to the atomic ratio $\mathrm{Ni} 44.3 \%, \mathrm{Ti} 46.4 \%, \mathrm{Nb} 9.3 \%$, the mass ratio is calculated to be 25.99:22.21:8.64, and the elemental $\mathrm{Ni}, \mathrm{Ti}$, and $\mathrm{Nb}$ elements weighing 140 mesh on the basis of mass ratio are mixed. Put into the mill jar and then add alcohol, so that the liquid surface to the mill tank more than a third and over the powder.

Then use some rubber balls with a 15:1 pellet ratio and a rotation speed of $200 \mathrm{rpm}$ to ball mill it for $0.5 \mathrm{~h}$, the mixture of powder and alcohol after the ball milling is removed to a beaker.The mill jar and ball are rinsed with alcohol and remaining powder is flushed into the beaker. It should be put in a vacuum oven, vacuum the oven and raise the temperature, morover, dry it at $80^{\circ} \mathrm{C}$ for $1 \mathrm{~h}$ until the powder is completely dry. After the vacuum is removed and the breaker should be taken out when the temperature is reduced to room temperature.

The $2 \mathrm{~mm}$ thick TC4 substrate is remove the surface of oil dirt using acetone, the surface of the substrate is polished clean, smooth by sandpaper and dried with a hairdryer blown, Prep $2 \mathrm{~mm}$ thick powder layer is precasted on TC4 substrate with $2 \mathrm{~mm}$ self-made squeegee and cladded with $\mathrm{Nd}$ :YAG laser, operating parameters setup are 100A current, $5 \mathrm{~ms}$ pulse width, $15 \mathrm{~Hz}$ frequency, $+20 \mathrm{~cm}$ positive defocus , $300 \mathrm{~mm} / \mathrm{min}$ scanning speed, and the overlap rate is $50 \%$, and the cladding layer is formed, then It can be smoothed with sandpaper.

\section{Results and discussion}

\subsection{Composition microstructure evolution}

The composition of the cladding layer was determined by EDS, as shown in table 1.

Table 1. Coating composition.

\begin{tabular}{|c|c|c|}
\hline elements & mass ratio $(\%)$ & atomic ratio $(\%)$ \\
\hline $\mathrm{Ti}$ & 38.29 & 45.97 \\
\hline $\mathrm{Ni}$ & 43.90 & 43.01 \\
\hline $\mathrm{Nb}$ & 17.80 & 11.02 \\
\hline
\end{tabular}

The coating composition is close to $44 \mathrm{Ni}-47 \mathrm{Ti}-9 \mathrm{Nb}[10]$.

Figure 1 and figure 2 show the composition distribution of $\mathrm{Ni}, \mathrm{Ti}$, and $\mathrm{Nb}$ in the coating. It can be seen that the elements in the coating are uniformly distributed, which means that the composition of the cladding layer is uniform. 


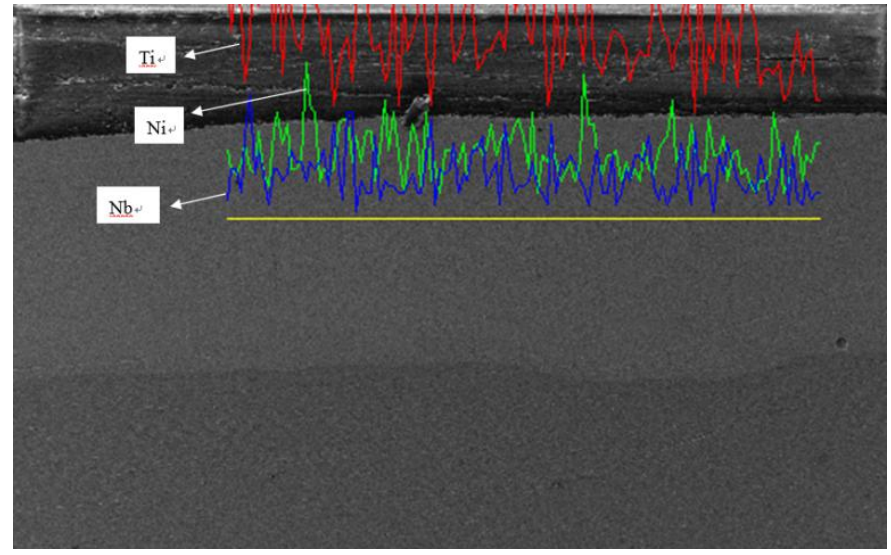

Fig. 1. Elemental distribution in the cladding (horizontal).

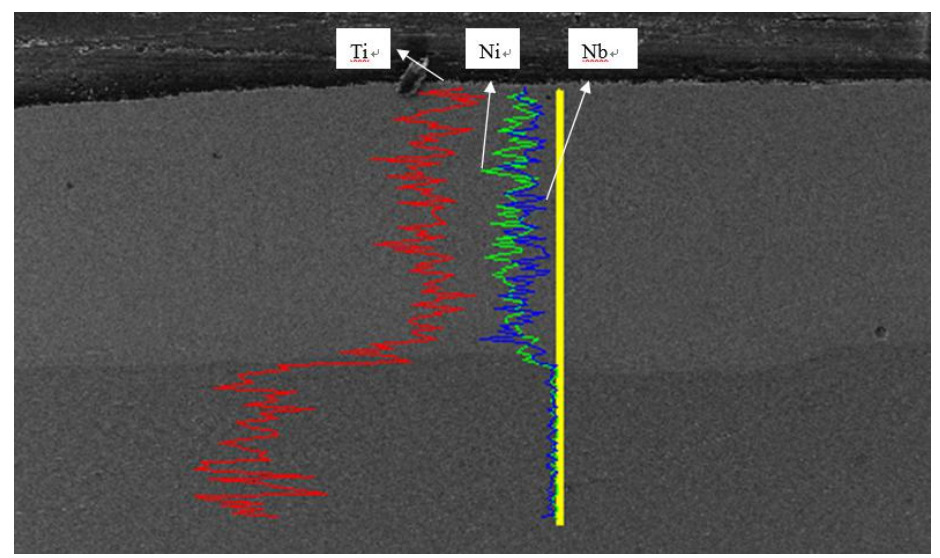

Fig. 2. Elemental distribution in the cladding (vertical).

From figure 2, it can be found that the content of the three elements in the coating and the substrate where the mutation occurs, this is because the main component of the matrix is $\mathrm{Ti}$ without $\mathrm{Ni}, \mathrm{Nb}$. So Ti suddenly increased and $\mathrm{Ni}, \mathrm{Nb}$ dips when the transition from the coating to the substrate.

When the energy of the laser beam is insufficient influenced by the laser, the crystal grains of the cladding layer are often coarse, as shown in figure 3.

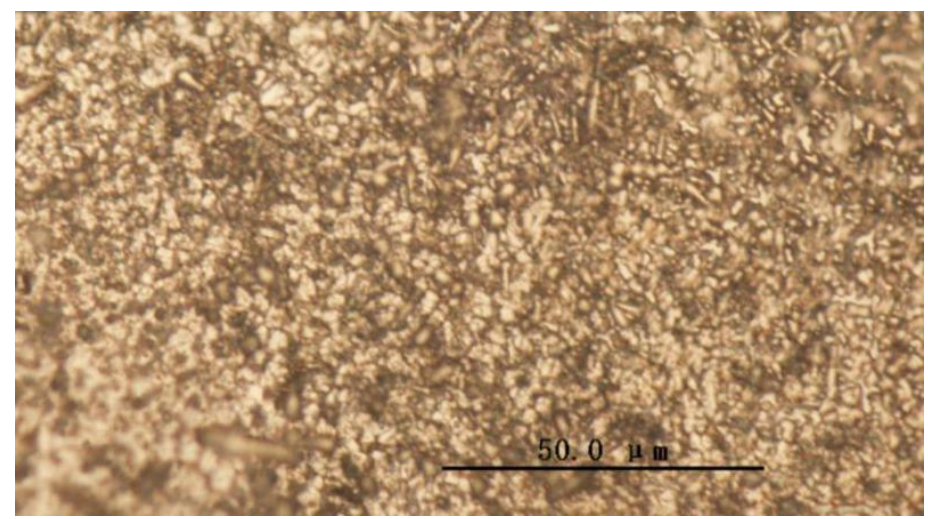

Fig. 3. Cladding layer of coarse grains in the microstructure. 
This is due to the fact that the temperature of the bath during laser irradiation is not sufficient, and various metals power is not fully mixed in the molten state. This solution can be improved by solution treatment. The specific method is to heat the sample at $900^{\circ} \mathrm{C}$ for two hours and then cool it in the furnace. Observing under the metallurgical microscope, the sample will undergo grain refinement after the solution is dissolved. The grid appears and the organization is dense, as shown in figure 4.

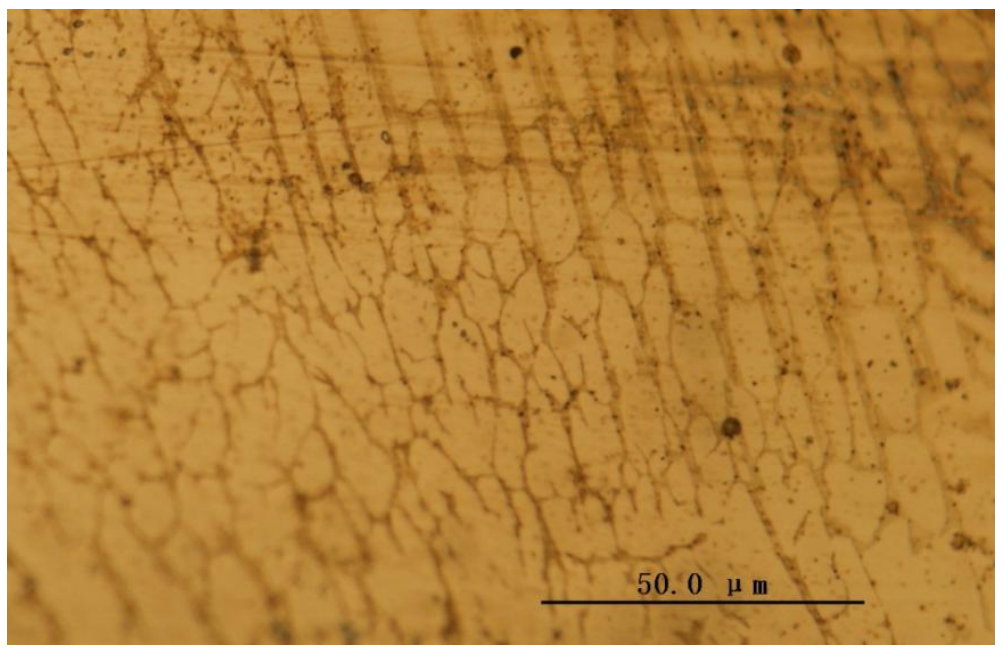

Fig. 4. Solid solution after microstructure.

\subsection{Performance analysis}

The sample was inlayed the resin to prepare a sample, and the micro-hardness of the transverse base surface was measured, and the hardness change law was analyzed. The microhardness load was $1000 \mathrm{~g}$ and the loading time was for $5 \mathrm{~s}$. The microhardness test uses a zero point at the junction of the cladding layer and the substrate, with the cladding direction being the positive direction. From the zero point to the cladding layer, each point of $50 \mu \mathrm{m}$ is taken to measure its hardness. The three points of hardness are averaged at the same distance to measure the hardness of the substrate. Substrate hardness changes less. The average hardness is taken from every $100 \mu \mathrm{m}$ to obtain the hardness distribution map. as shown in figure 5 .

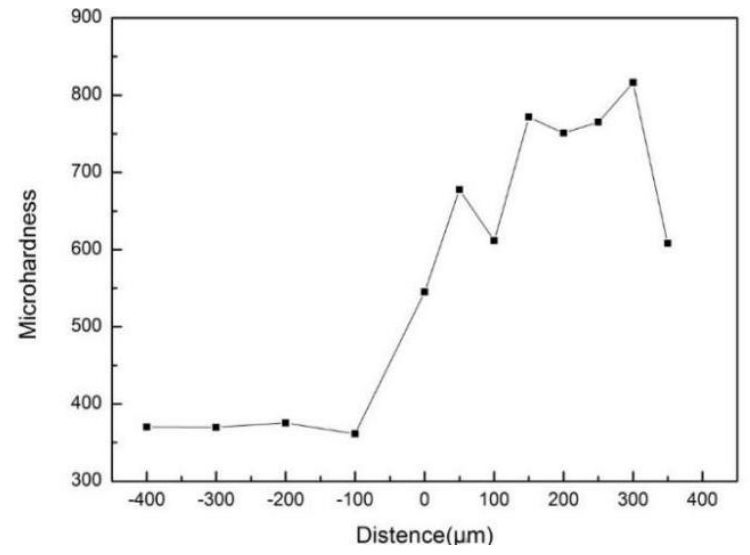

Fig. 5. Microhardness profile. 
It can be seen from figure 5 the hardness of cladding layer is significantly higher than that of substrate. The upward hardness from substrate gradually increases from the heat affected zone, which the reason of hardness increase of the heat affected zone is the effect of laser processing overcooling producing grain refinement, and the hardness of the sample from the heat affected zone up to the cladding layer is continued increase mainly duing to an increase in hardness caused by the composition change. The slight decrease of surface hardness of cladding layer is resulted by the fact that surface of cladding layer is oxidized to form an oxide layer and the composition is not uniform.

\subsection{Tribological properties}

The sample room temperature friction and wear test is conducted on a HSR-2M high-speed reciprocating friction tester. The ball is GCr15, diameter $5 \mathrm{~mm}$, the load is $520 \mathrm{~N}$, reciprocating frequency is $5 \mathrm{~Hz}$, stroke is $4.6 \mathrm{~mm}$, test time is for $10 \mathrm{~min}$, and the friction coefficient is dynamically acquired. As shown in figure 6 .

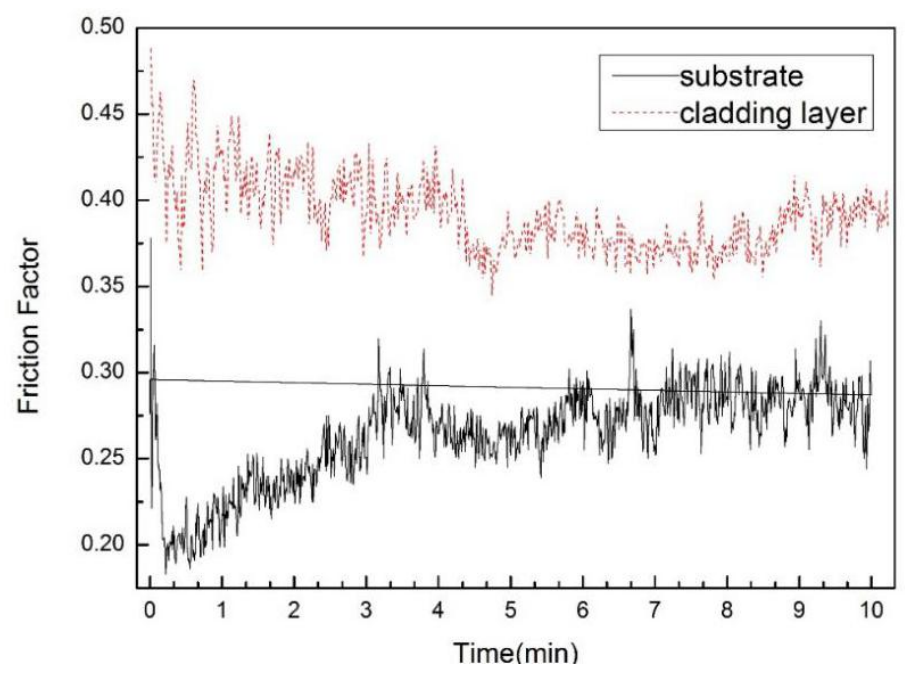

Fig. 6. Friction factor history of cladding coating and substrate.

It can be seen that the friction coefficient of the cladding layer is higher than that of the substrate from figure.6, because the flatness of the substrate is higher than that of the cladding layer. The friction coefficient of TC4 starts to increace in the late increase. This is due to the surface of the TC4 substrate had been destroyed and its surface roughness has increased. The friction coefficient curve of the cladding layer fluctuates greatly, indicating that the surface of the substrate was damaged. It can be seen from the experiment that the wear scar on the coating is shallow, the amount of wear is small, and the wear resistance is better.

\section{Results}

Laser cladding technology generates Ni-Ti-Nb alloy coating on the surface of TC4 titanium alloy. Different combinations of the three elements will form different microstructures and are mainly divided into three types of microstructures. The surface hardness and wear resistance of the material are significantly improved. Affected by composition and grain refinement, the hardness of the coating is twice the hardness of the substrate and higher than that of the heat-affected zone. The wear-resistance of the matrix is also significantly 
improved. The analysis of the change trend of its friction coefficient at different stages shows that the coating is more stable than the substrate and the wear resistance is better.

\section{Acknowledgement}

This work was supported by Fundamental Research Funds for the Central Universities of China (No. 3232016354).

\section{References}

1. LI Xianmin, LIU Li, DONG Jie, ect. Discussion on economic analysis and decreasing cost process of titanium and titanium alloys [J]. MATERIALS CHINA. 2015 05:401-406.

2. Liu Qinghui,Xu Xiaojing,Ge xiaolan,ect. Research of Laser Alloying Ti-Si-C Coating on TC4 Titanium Alloy [J]. CHINESE JOURNAL OF RARE METALS. 2016(06): 546-551.

3. Ding R, Guo Z X. Microstructural evolution of a Ti-6Al-4V alloy during $\beta$-phase processsing:xperimental and simulative investigations[M]. 2004: 172-179.

4. XU Liang, MA Chuang, ZHOU Song, ect. Influence of loading direction on fatigue performance of TC4 titanium alloy laser weld [J]. TRANSACTIONS OF THE CHINA WELDING INSTITUTION. 2017(06): 15-18.

5. N. Popov N, F. Lar Kin V, A. Ogorodnikov V, et al. Effect of shock-wave loading on mechanical and thermomechanical characteristics of shape-memory alloys $45 \mathrm{Ti}-45 \mathrm{Ni}-$ $10 \mathrm{Nb}$ and $43 \mathrm{Ti}-46 \mathrm{Ni}-8 \mathrm{Nb}-3 \mathrm{Zr}[\mathrm{M}]$. 2016: 962-968.

6. ZHANG Jun. Research on cavitation erosion resistance of NiTi coating[D]. Xi'an Shiyou University, 2013

7. Ye H Z, Liu R, Li D. Wear and friction of a new wear-resistant material: TiNi-ba sed composites[M]. 2001: 987-994.

8. ZHAO Hui, WANG Baoting, DU Chunyan,ect. Research progress of surface modification technology of TC4 titanium alloy [J]. Journal of Shenyang Ligong University. 201702 : 74-77.

9. Feng Hui, Li Jianfeng ,Sun Jie,ect. Study on remanufacturing repair of damaged crank shaft Journal Surface by Laser Cladding[J]. CHINESE JOURNAL OF LASERS. $201408: 86-91$.

10. Dong Zhi zhong, Liu Wenxi, Jia Di, ect. Corrosion Resistance of the Ni-Ti-Nb Based Shape Memory Alloys[J]. RARE METAL MATERIALS AND ENGINEERING. 2000, Vol.29 (3): 182-184. 